\title{
Evaluation of university scientific research ability Based on T-S fuzzy neural network and DEA model
}

\author{
Yi-Yong YE \\ School of Economics \& Management, Wuyi University, JiangMen, 529020, China \\ 30117406@qq.com
}

Keywords : Fuzzy system; Neural network; DEA; Scientific research

\begin{abstract}
This paper construct the evaluation index system of university scientific research ability from two aspects of research input and output, and then combined with fuzzy theory and neural network advantages, proposed the evaluation of scientific research ability of T-S model based on fuzzy neural network, the data analysis shows that, the model can accurately predict the status of scientific research ability in different colleges and universities; on the basis of the classification, further using the DEA algorithm, do in-depth comparative analysis on the scale efficiency and technical efficiency of the scientific research ability of various types of colleges and universities, points out the influence of non DEA effective factors, and give the corresponding improvement measures. Empirical analysis shows that the evaluation model based on T-S FNN and DEA has higher accuracy and stronger maneuverability.
\end{abstract}

\section{Introduction}

With the development of social economy, colleges and universities play a more and more significant role in the process of serving the local economy, in addition to training high quality talents through teaching service, scientific research in colleges and universities has gradually become an important driving force for the development of local economy, therefore, as the main body of knowledge and technology innovation as well as the important source of enterprise innovation, more and more attention is paid to the function of scientific research in colleges and universities. At the same time, scientific research ability, as an important embodiment of the core competitiveness of colleges and universities, plays a very important role in the current and future development, and has become one of the key indicators to reflect the comprehensive strength of colleges and universities. So, it has very important practical significance to make reasonable and accurate evaluation of scientific research ability, objective and fair evaluation result, is not only beneficial to clear the direction of the construction and management of college scientific research ability, but also conducive to timely find problems and the insufficiency, actively promote the healthy and orderly development of scientific research management and continuously improve.

\section{Literature Review}

At present, many scholars have studied the evaluation of scientific research ability in universities. The research contents are mainly focused on two aspects, one is the construction of evaluation system, such as Xu Min and Duan Baobin construct the evaluation system in four aspects of research equipment and conditions, research teams, research management capabilities and research output ${ }^{[1,2]}$; and the other is to select suitable evaluation method, as some scholars use the entropy method, Waring distribution model, the method of rough set, SVM, fuzzy comprehensive evaluation method etc. to make scientific evaluation of research ability, the evaluation results are more objective and rational, and provides a favorable basis in scientific research management and decision making ${ }^{[2,3,4,5,6]}$.

The above studies were analyzed from different perspectives and levels, and made some progress. Because the evaluation of scientific research ability is a nonlinear and complicated system, 
the evaluation process is easily affected by various objective or subjective factors, therefore, if using a simulation based on mathematical model of the parameter hypothesis, is difficult to get accurate evaluation results. So, this article put forward the processing method of evaluating step by step, first from the angle of the longitudinal, put all the scientific research ability of colleges and universities from macro level classification, determine the type of all the colleges and universities, then made comparison of each kind of samples from the horizontal angle, through the above analysis, not only can be concluded that the overall ranking of some colleges and universities in all samples, but also can grasp the colleges and universities in the samples of the same type of advantages and disadvantages, which can provide a reference for further improvement.

\section{Construction of evaluation system of scientific research ability in university}

The construction of scientific research ability evaluation system is the foundation of implementing evaluation, due to the influence factors of regional economic development level, the school development strategy, the development level and the degree of attention in scientific research, various universities use different scientific research evaluation and evaluation standard,some scholars put forward through scientific research projects, research papers, books, awards and patents of five quantitative indicators to measure the scientific research of university teachers and school overall situation ${ }^{[3]}$, some scholars believe that it would be more comprehensive to consider from two aspects of the input and output index ${ }^{[7]}$, and the other scholars put forward from the scientific research team, academic influence and the scientific research activity of three aspects to evaluate the ability of scientific research ${ }^{[8]}$. Different evaluation system to a certain extent, can reflect the scientific characteristics of some types of colleges and universities.

Based on the existing research results, and considering the comparability and availability of data, construct the evaluation index system from two angles of research input and output, and divided the university's scientific research ability into five grades: excellent (1), good (2), moderate (3), poor (4), very poor (5), specifically including the following aspects:

(1) Teaching and scientific research personnel (X1) : refers to the faculty of on-the-job enrolled at colleges and universities, engaged in teaching and research work, and service for scientific research.

(2) Investment of scientific research funds (X2) : can be divided into the government, enterprises and institutions and other funds.

(3) Total number of subjects approved (Y1) : Including two categories of vertical and horizontal topics.

(4) Academic paper (Y2): Academic paper is a very important output index of scientific research for innovation activities and scientific research in universities.

(5)Technology transfer income (Y3): technology transfer is the key research achievements into practical productive forces, including the contract number and the transfer of revenue. Technology transfer income ultimately reflects the university scientific research innovation achievements of economic value and social value.

(6)Scientific research achievement award (Y4): scientific research achievement award is to get recognized by the outside world and rewarded outstanding scientific achievements, high-level scientific research achievements can reflect the school scientific research strength.

(7)Science and technology monograph (Y5): Scientific and technological work is a very important indicator of the output of scientific research innovation activities in Colleges and universities.

\section{T-S fuzzy neural network theory}

\subsection{T-S fuzzy model}

The main problems in multi-dimensional fuzzy reasoning are too much inference rules. For this reason, a new fuzzy inference model, called Takagi - Sugeno (T-S) fuzzy model, is proposed by 
Takagi and Sugeno in $1985^{[10]}$. T-S fuzzy system is a kind of fuzzy system with strong adaptive ability. The advantages of this system are embodied in two aspects: first, it can be updated automatically, and the two is to modify the membership function of fuzzy subsets step by step. T-S fuzzy systems generally use the following "Then-If" rules to define, in the case of the rule $R^{i}$, fuzzy reasoning as follows:

$$
R^{i}: \text { If } x_{1} \text { is } A_{1}^{i}, x_{2} \text { is } A_{2}^{i}, \ldots x_{k} \text { is } A_{k}^{i} \text {, then } y_{i}=p_{0}^{i}+p_{1}^{i} x_{1}+\ldots+p_{k}^{i} x_{k}
$$

Where $A_{j}^{i}$ is a fuzzy set of fuzzy systems, where $p_{j}^{i}(j=1,2, \ldots k)$ is the fuzzy system parameters; $y_{i}$ is the output according to the fuzzy rule, the input section (if section) is fuzzy, the output section(then section) is determined, and the fuzzy inference indicates that the output is a linear combination of the inputs.

Assuming that the input variable is $x=\left[x_{1}, x_{2}, \ldots x_{k}\right]$, the membership degree of each input variable $x_{j}$ is calculated according to the fuzzy rule:

$$
u A_{j}^{i}=\exp \left(-\left(-x_{j}-c_{j}^{i}\right)^{2} / b_{j}^{i}\right) \quad j=1,2, \ldots k ; i=1,2 \ldots n
$$

In the formula, $c_{j}^{i}, b_{j}^{i}$ respectively for the center and width of the membership function; $k$ is the number of input parameters, for $n$ is the number of fuzzy subsets.

Use the multiplication operator as fuzzy operator, and calculate the fuzzy membership degree:

$w^{i}=u A_{j}^{1}\left(x_{1}\right) * u A_{j}^{2}\left(x_{2}\right) * \ldots u A_{j}^{k}\left(x_{k}\right) \quad i=1,2, \ldots n$

According to fuzzy calculation results, calculate the output value of the fuzzy model :

$$
y_{i}=\sum_{i=1}^{n} w^{i}\left(p_{0}^{i}+p_{1}^{i} x_{1}+\ldots+p_{k}^{i} x_{k}\right) / \sum_{i=1}^{n} w^{i}
$$

\subsection{Neural Networks}

BP neural network is a kind of multi-layer feed forward network which is trained by error back propagation algorithm, its basic structure includes an input layer, a hidden layer and output layer, the core idea is using the output error to estimate the output layer directly leading layer of the error, and then the error estimation of another layer of error, so by layer back propagation down, all other layers of the error estimate is obtained, then according to the error to gradually adjust the network weights and threshold, and ultimately making minimal square sum of error of the network output and the expected output. BP network has a strong self-learning ability, which can simulate the logical quantity relation between input and output indicators through different learning rules.

\subsection{T-S Fuzzy Neural Network}

Fuzzy systems in the process of modeling often exists the problems such as lack of learning ability, identification of complicated, model parameters are difficult to optimize etc., and artificial neural network has the combination of self-learning, self organization and adaptive ability, and have a strong non-linear processing ability. so,construction of T-S Fuzzy Neural Network can effectively play the fuzzy logic and neural network to their respective advantages and make up for their disadvantages. Standard T-S fuzzy neural network structure is shown in Figure 1.

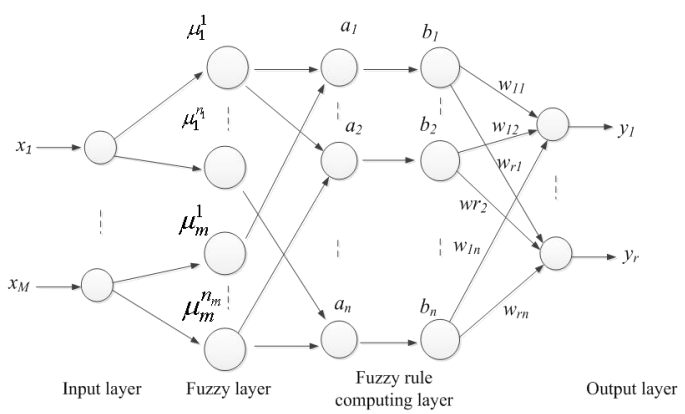

Fig. 1 the structure of T-S fuzzy neural network 
T-S fuzzy neural network is composed of four layers, which are input layer, fuzzy layer, fuzzy rule computing layer and output layer. The calculation principle of each layer is as follows:

(1)The input layer is connected with the input vector $x_{j}$, the number of nodes is the same as the dimension of the input vector.

(2)The fuzzy layer uses the membership function(2) to fuzzy the input value to get the fuzzy membership degree $\mu$.

(3)Fuzzy rule computing layer use fuzzy multiplication formula (3) to calculate $w$.

(4)The output layer using formula (4) to calculate the output of the fuzzy neural network.

According to the principle, the learning algorithm of T-S fuzzy neural network is as follows:

(1) error calculation

$e=\frac{1}{2}\left(y_{d}-y_{c}\right)^{2}$

In the formula, $y_{d}$ is the expected output of the network; $y_{c}$ is the actual output of the network; $e$ is the error of the expected output and the actual output.

(2)coefficient correction

$$
\begin{aligned}
& p_{j}^{i}(k)=p_{j}^{i}(k-1)-\alpha \frac{\partial e}{\partial p_{j}^{i}} \\
& \frac{\partial e}{\partial p_{j}^{i}}=\left(y_{d}-y_{c}\right) w^{i} / \sum_{i=1}^{m} w^{i} * x_{j}
\end{aligned}
$$

In the formula, $p_{j}^{i}$ is the neural network coefficient, $\alpha$ is the network learning rate, the $x_{j}$ is the network input parameter, and the $w^{i}$ is an input parameter of membership multiplication.

(3) parameter correction

$$
\begin{aligned}
& c_{j}^{i}(k)=c_{j}^{i}(k-1)-\beta \frac{\partial e}{\partial c_{j}^{i}} \\
& b_{j}^{i}(k)=b_{j}^{i}(k-1)-\beta \frac{\partial e}{\partial b_{j}^{i}}
\end{aligned}
$$

In the formula, $c_{j}^{i}, b_{j}^{i}$ are the center and width of the membership function respectively ${ }^{[11]}$.

\section{DEA model}

Data envelopment analysis(DEA) is an important field in the research of the intersection of operations research, management science and mathematical economics. It was created by Charnes and Cooper in 1978. DEA use mathematical programming model to evaluate the relative effectiveness of the decision making units with multiple inputs and multiple outputs. DMU is effective for DEA, in essence, is to determine whether the DMU is located in the production of the possible set of the "front face". When using DEA to evaluate the efficiency of DMU, we can get a lot of management information which has a profound economic meaning and background in economics. Therefore, the research on DEA has attracted a large number of scholars ${ }^{[12,13]}$.

\section{1. $C^{2} R$ model}

Suppose there are $n$ units of DMU (decision-making unit), each decision unit has $m$ kind of "input", and $n$ kind of "output" .

$X_{j}=\left(x_{1 j}, x_{2 j}, \cdots, x_{m j}\right)^{T} \geq 0$ and $Y_{j}=\left(y_{1 j}, y_{2 j}, \cdots, y_{s j}\right)^{T} \geq 0$ respectively for the decision making unit (DMU $j)$ input index and output index $(j=1,2 \ldots, \mathrm{n}$,$) , in the premise of satisfying the$ ordinary axiom, the convexity axiom, the axiom of null and void, the axiom of convexity and the axiom of the smallest, established the $C^{2} R$ model with non Archimedes infinitesimal ${ }^{[14]}$ : 


$$
\left(D_{C^{2} R}^{2}\right)\left\{\begin{array}{l}
\min \left[\theta-\varepsilon\left(\hat{e}^{T} s^{-}+e^{T} s^{+}\right)\right]=V^{0} \\
\sum_{j=1}^{n} X_{j} \lambda_{j}+s^{-}=\theta X_{0} \\
\sum_{j=1}^{n} Y_{j} \lambda_{j}-s^{+}=Y_{0} \\
\lambda_{j} \geq 0, j=1,2, \cdots, n \\
s^{+} \geq 0, s^{-} \geq 0 \\
\hat{e}=(1,1, \cdots 1,1)^{T} \in E_{m} \\
e=(1,1, \cdots 1,1)^{T} \in E_{s}
\end{array}\right.
$$

The model can evaluate the comprehensive efficiency of each decision-making unit of technology and scale, known as the overall efficiency, set the optimal solution for the model is: $\theta_{0}$, $\lambda_{0}, s_{0}^{+}, s_{0}^{-}$, Its evaluation criteria are:

(1) if the optimal value of $V_{0}$ is $\theta_{0}=1$, and $s_{0}^{+} \neq 0$ or $s_{0}^{-} \neq 0$, then, the decision making unit is weak DEA effective. That is, In the economic system, which is composed of $n$ decision making units, the input $X_{0}$ can reduce $s_{0}^{-}$and maintain the output of the original $Y_{0}$, or increase the output $s_{0}^{+}$in the case of input $X_{0}$.

(2) if the optimal value of $V_{0}$ is $\theta_{0}=1$, and $s_{0}^{+}=0, s_{0}^{-}=0$, then, the decision making unit is DEA effective. That is, based on the original input $X_{0}$, obtained output $Y_{0}$ has reached the optimal.

(3) if the optimal value of $V_{0}$ is $\theta_{0}<1$, then the decision making unit is DEA invalid. In this case, the combination will be put into the original input $V_{0} * \theta_{0}$, and to maintain the origin output of $Y_{0}$.

(4) If there is $\lambda^{*}{ }_{j}$, making $\sum_{j=1}^{n} \lambda^{*}{ }_{j}=1$ was established, then the decision unit for the scale of benefits unchanged; if $\sum_{j=1}^{n} \lambda^{*}{ }_{j}>1$, then the decision making units as diminishing scale; if $\sum_{j=1}^{n} \lambda^{*}{ }_{j}<1$, then the decision making unit for increasing economies of scale.

\section{2. $\mathrm{C}^{2} \mathrm{GS}^{2}$ model}

By $\mathrm{C}^{2} \mathrm{R}$ model, we can determine whether a decision making unit is DEA efficient. If for DEA effective, can be sure that, the production and operation is in technology and scale effectively at the same time . But if a $\mathrm{DMU}_{\mathrm{J}}$ is Non-DEA efficient, then, it is difficult to determine the further it will work for technology, so set up $\mathrm{C}^{2} \mathrm{GS}^{2}$ model only for evaluation of relative technology effective ${ }^{[14]}$ :

$$
\left(D_{\mathrm{C}^{2} \mathrm{GS}^{2}}^{2}\right)\left\{\begin{array}{l}
\min \left[\theta-\varepsilon\left(\hat{e}^{T} s^{-}+e^{T} s^{+}\right)\right]=V^{0} \\
\sum_{j=1}^{n} X_{j} \lambda_{j}+s^{-}=\theta X_{0} \\
\sum_{j=1}^{n} Y_{j} \lambda_{j}-s^{+}=Y_{0} \\
\sum_{j=1}^{n} \lambda_{j}=1 \\
\lambda_{j} \geq 0, j=1,2, \cdots, n \\
s^{+} \geq 0, s^{-} \geq 0 \\
\hat{e}=(1,1, \cdots 1,1)^{T} \in E_{m} \\
e=(1,1, \cdots 1,1)^{T} \in E_{s}
\end{array}\right.
$$

The model calculates the DMU efficiency of pure technical efficiency, it reflects the pure technical benefits of DMU, set the optimal solution for the model is: $\theta_{0}, \lambda_{0}, s_{0}^{+}, s_{0}^{-}$, the criteria for evaluation is: 
(1) if the optimal value of $V_{0}$ is $\theta_{0}=1$, and $s_{0}^{+} \neq 0$ or $s_{0}^{-} \neq 0$, then the decision making unit is weak DEA efficient

(2) if the optimal value of $V_{0}$ is $\theta_{0}=1$, and $s_{0}^{+}=0, s_{0}^{-}=0$, then the decision making unit is DEA effective.

(3) if the optimal value of $V_{0}$ is $\theta_{0}<1$, then the decision making unit is DEA invalid.

\subsection{DMU non DEA effective projection adjustment method}

Set up $\left(X_{0}, Y_{0}\right)$ for the input and output of a decision unit, and $\left(X_{0}^{\prime}, Y_{0}^{\prime}\right)$ is the projection of $\left(X_{0}, Y_{0}\right)$ on the relative effective surface of DEA, the adjustment quantity of the input and output are as follows:

$$
\begin{aligned}
& \Delta X=X_{0}^{\prime}-X_{0}=\left(\theta_{0}-1\right) * X_{0}-S_{0}^{-} \\
& \Delta Y=Y_{0}^{\prime}-Y_{0}
\end{aligned}
$$

The adjusted index can be used as the forecast value of the input and output indexes of the next decision stage. So with the help of projection, we can find out the system needs to be improved in the mass, and to guide system adjustment ${ }^{[14]}$.

\section{Empirical analysis}

\subsection{Data collection and collation}

The data from "2013 higher school science and technology statistics compilation", including 28 undergraduate colleges in GuangDong province at various levels, as shown in Table 1, last column for the scientific classification of colleges and universities.

\begin{tabular}{|c|c|c|c|c|c|c|c|c|c|}
\hline order number & School name & $\mathrm{X} 1$ & $\mathrm{X} 2$ & Y1 & $\mathrm{Y} 2$ & Y3 & \multicolumn{3}{|c|}{ Y4 Y5 grade } \\
\hline 1 & Shantou University & 2935 & 86190 & 882 & 1180 & 1141 & 9 & 0 & 3 \\
\hline 2 & South China Agricultural University & 1470 & 345870 & 1936 & 2067 & 2860 & 15 & 13 & 3 \\
\hline 3 & Guangdong Ocean University & 1128 & 78418 & 619 & 544 & 0 & 13 & 3 & 4 \\
\hline 4 & Guangzhou Medical College & 5064 & 162023 & 1466 & 2686 & 0 & 7 & 5 & 3 \\
\hline 5 & South China University of Technology & 3003 & 1402147 & 5679 & 5935 & 21471 & 33 & 15 & 1 \\
\hline 6 & Guangdong Medical College & 2203 & 84140 & 703 & 1226 & 0 & 2 & 2 & 4 \\
\hline 7 & Guangzhou University of Chinese Medicine & 4498 & 149947 & 1132 & 2680 & 10 & 15 & 4 & 3 \\
\hline 8 & shaoguan university & 396 & 13177 & 116 & 237 & 0 & 0 & 0 & 5 \\
\hline 9 & Huizhou University & 314 & 15529 & 300 & 271 & 2 & 0 & 4 & 5 \\
\hline 10 & Hanshan normal university & 322 & 17461 & 285 & 320 & 0 & 0 & 1 & 5 \\
\hline 11 & Zhanjiang normal university & 500 & 21460 & 258 & 350 & 0 & 1 & 0 & 5 \\
\hline 12 & Sun Yat-sen University & 13014 & 1516673 & 6608 & 9655 & 2732 & 38 & 46 & 1 \\
\hline 13 & ZhaoQing University & 337 & 18086 & 94 & 529 & 250 & 0 & 3 & 5 \\
\hline 14 & Jiaying University & 342 & 19177 & 124 & 460 & 0 & 1 & 1 & 5 \\
\hline 15 & Guangdong Polytechnic Normal University & 273 & 16265 & 61 & 326 & 273 & 0 & 2 & 5 \\
\hline 16 & Shenzhen University & 972 & 264104 & 711 & 909 & 4230 & 4 & 4 & 3 \\
\hline 17 & Guangzhou University & 951 & 242760 & 855 & 735 & 260 & 4 & 6 & 4 \\
\hline 18 & Zhongkai university of agriculture and engineering & 489 & 68232 & 721 & 1149 & 0 & 18 & 0 & 4 \\
\hline 19 & Guangdong petroleum and Chemical Engineering Institute & 540 & 51654 & 434 & 478 & 0 & 0 & 0 & 5 \\
\hline 20 & Dongguan University of technology & 431 & 57346 & 318 & 275 & 0 & 0 & 0 & 5 \\
\hline 21 & Guangdong University of Technology & 1606 & 297105 & 1611 & 2568 & 110 & 6 & 8 & 3 \\
\hline 22 & Foshan university & 676 & 79988 & 411 & 426 & 0 & 1 & 0 & 5 \\
\hline 23 & Southern Medical University & 3239 & 286670 & 1101 & 2285 & 36510 & 12 & 13 & 2 \\
\hline 24 & Guangzhou University of Education & 131 & 8213 & 90 & 200 & 0 & 1 & 4 & 5 \\
\hline 25 & Guangdong Pharmaceutical University & 1583 & 63990 & 415 & 948 & 50 & 2 & 0 & 4 \\
\hline 26 & Jinan University & 2791 & 438998 & 1405 & 4042 & 25493 & 6 & 1 & 2 \\
\hline 27 & Wuyi University & 411 & 23475 & 301 & 320 & 95 & 0 & 2 & 5 \\
\hline 28 & South China Normal University & 1179 & 223440 & 691 & 1564 & 312 & 9 & 5 & 3 \\
\hline
\end{tabular}

Table 1 evaluation index data of scientific research ability in Universities 


\subsection{T-S fuzzy neural network model training and testing}

\section{(1)Randomly generated training samples and test samples}

Due to the sample data without temporal sequence, Therefore, in order to reflect the generality of the evaluation model to the data, 23 samples were randomly selected from 28 samples as training samples, used to determine the model parameters, and the remaining 5 were used as test samples to test the effectiveness of the model.

(2) Data preprocessing

In order to meet the basic requirements of the model for processing data, the data should be standardized to solve the comparability between the data. In this paper, we use the method of deviation standardization to linear transformation of the original data, make the transformed value map to $[0,1]$, and keep the original quantity relation, the transformation formula is shown below:

$Y_{i}=\left(X_{i}-\min \right) /(\max -\min )$

Among them, $Y_{i}$ is the sample $i$ normalized values, $X_{i}$ is the value of the sample $i$, min for sample minimum, max for samples maximum . But this method has a drawback, when there is a new sample data to join, the data of the maximum and the minimum may change, need to recalculate the value of $Y_{i}$.

when predicting or assessment is completed, then use the normalized method to restore the data to get the true value, the specific data processing can be directly call Matlab toolbox Mapminmax function to complete.

(3) initial t-s fuzzy neural network parameters

The number of input and output nodes of the fuzzy neural network is determined by the number of input and output indexes of the training samples, since the dimension of the input data is 7 , the dimension of output data is 1 , so to determine the number of input nodes of networks for 7 and 1 as the number of output nodes. Then according to the number of network input and output nodes, combined with the research results of the related references ${ }^{[15]}$, use cycle comparison algorithm to determine the best network hidden layer nodes number as 10 , so the network structure is determined to be 7-10-1, random initialization of fuzzy membership degree function center for $\mathrm{c}$, width for $\mathrm{b}$, and the coefficient is $p_{0}-p_{11}$.

About model parameter selection problems, according to the basic principle of fuzzy system and neural network, t-s fuzzy neural network of all the nodes and their parameters is on behalf of practical significance, therefore, in the building of network initialization phase, we can use the fuzzy or qualitative knowledge of the system to determine the parameters of the initial value or value range, so as to reduce the number of operation program, improve operational efficiency, and speed up the convergence rate of the t-s fuzzy neural network.

(4)Model training, determining parameters

Mainly includes parameter fuzzy, fuzzy membership degree calculation and fuzzy parameter correction process. The 23 samples were randomly selected as the training samples for training the T-S fuzzy neural network model, and determine the model training time is 500.The training results are shown in figure 2.

\section{(5)Model test}

The rest 5 samples as the test sample, plug in the trained model to calculate and test of the model prediction effect. Test results as shown in figure 3. 


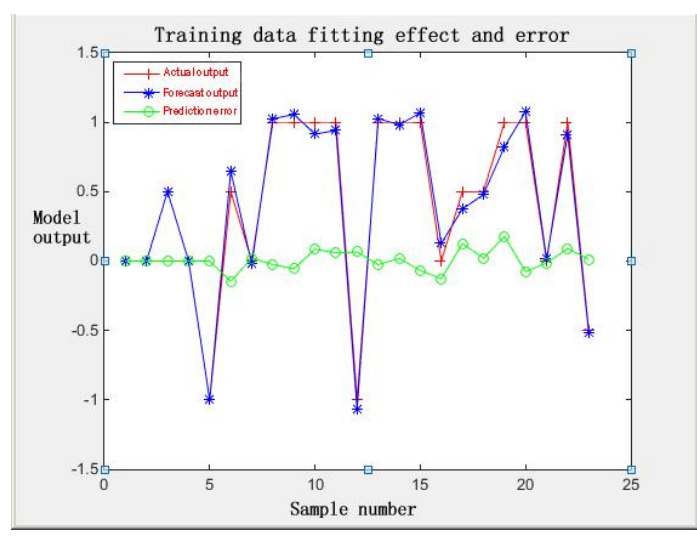

Fig. 2 training effect and error diagram

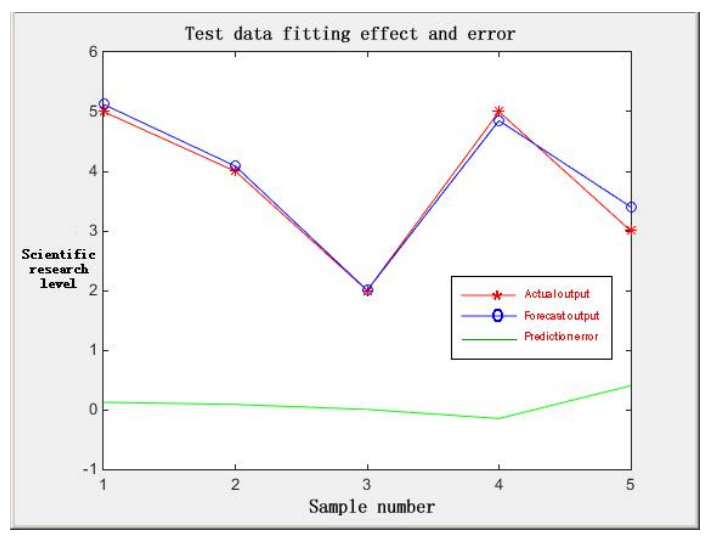

Fig. 3 fitting effect of test sample data

From figure 2 the fitting curve effect and error curve we can know, based on the t-s fuzzy neural network to the fitting effect of sample data is ideal, with a few samples slightly off the actual value, the rest of the sample can match the actual value, which shows that model hypothesis and build not only meet the needs of theory, in practice is also reasonable, conform to the actual situation.

Figure 3 is the predicted classification result of five test samples, in addition to the sample 5 forecasts vary slightly, the remaining four samples in complete accord with the actual classification, general prediction effect is very accurate. It means that the T-S based fuzzy neural network has a good generalization ability, it can make accurate judgments to the new samples based on the study of the history of the data.

In summary, through the T-S fuzzy neural network model, we can classify the scientific research ability of universities from the longitudinal perspective, and get a class of scientific research ability of a certain university. But the model can not describe the excellent or good details of the scientific research, also we don't know our advantages and disadvantages while compared to the same type or the same level of other colleges and universities. Therefore, this paper continue to use the DEA model, to make in-depth comparative analysis of the classification of samples.

\subsection{DEA evaluation analysis}

According to the first phase of the T-S fuzzy neural network classification results, select the samples of rating 5, as table 2 shows, using DEA C2R and C2GS2model to solve (other grades of sample processing procedure is the same). The computational results are shown in Table 3, Table4, Table8.

Table 2 sample data for Level 5

\begin{tabular}{ccccccccc}
\hline School Name & DMU & X1 & X2 & Y1 & Y2 & Y3 & Y4 & Y5 \\
\hline shaoguan university & DMU1 & 396 & 13177 & 116 & 237 & 0 & 0 & 0 \\
\hline Huizhou University & DMU2 & 314 & 15529 & 300 & 271 & 2 & 0 & 4 \\
\hline hanshan normal university & DMU3 & 322 & 17461 & 285 & 320 & 0 & 0 & 1 \\
\hline zhanjiang normal university & DMU4 & 500 & 21460 & 258 & 350 & 0 & 1 & 0 \\
\hline ZhaoQing University & DMU5 & 337 & 18086 & 94 & 529 & 250 & 0 & 3 \\
\hline Jiaying University & DMU6 & 342 & 19177 & 124 & 460 & 0 & 1 & 1 \\
\hline Guangdong Polytechnic Normal University & DMU7 & 273 & 16265 & 61 & 326 & 273 & 0 & 2 \\
\hline Guangdong petroleum and Chemical Engineering & \multirow{2}{*}{ DMU8 } & 540 & 51654 & 434 & 478 & 0 & 0 & 0 \\
\hline Institute & & & & \multirow{2}{*}{0} & & & \\
\hline Dongguan University of technology & DMU9 & 431 & 57346 & 318 & 275 & 0 & 0 & 0 \\
\hline foshan university & DMU10 & 676 & 79988 & 411 & 426 & 0 & 1 & 0 \\
\hline Guangzhou University of Education & DMU11 & 131 & 8213 & 90 & 200 & 0 & 1 & 4 \\
\hline Wuyi University & DMU12 & 411 & 23475 & 301 & 320 & 95 & 0 & 2 \\
\hline
\end{tabular}


Table 3 results of $C^{2} R$ model

\begin{tabular}{|c|c|c|c|c|c|c|c|c|c|c|c|}
\hline DMU & $s_{1}^{-}$ & $s_{2}^{-}$ & $s_{1}^{+}$ & $s_{2}^{+}$ & $s_{3}^{+}$ & $s_{4}^{+}$ & $s_{5}^{+}$ & $\theta$ & $\sum \lambda_{j}^{*}$ & DEA effectiven & Ne \\
\hline DMU1 & 0.000 & 000 & 0.000 & 0.000 & 4.688 & 0.000 & 1.297 & 0.862 & 0.5 & fic & Increasing scale \\
\hline DMU2 & 0.000 & 0.000 & 0.000 & 0.000 & 0.000 & 0.000 & 0.000 & 1.000 & 1.000 & $\mathrm{DE}$ & \\
\hline DMU3 & 0.000 & 0.000 & 0.000 & 0.000 & 0.000 & 0.000 & 0.000 & 1.000 & 1.000 & $\overline{\mathrm{DE} A}$ & \\
\hline DMU4 & 0.000 & 0.000 & 0.000 & 19.289 & 0.588 & 0.000 & 5.455 & 0.823 & 1.574 & DEA & \\
\hline DMU5 & 0.000 & 0.000 & 0.000 & 0.0 & 00 & 0.000 & & 1.000 & 1.000 & & \\
\hline DM & -69.779 & 0.000 & 12.2 & 0.0 & 22.873 & 0.0 & 4.474 & 0.892 & 1.491 & & \\
\hline J7 & 000 & 0.000 & 0.000 & 0.00 & 0. & 0.000 & 0.000 & 1.000 & 1.000 & $\mathrm{DF}$ & \\
\hline DMU8 & 0.000 & 0.000 & 0.000 & 5.415 & 20.535 & 0.000 & 1.727 & 0.536 & 1.511 & DEA & g scale \\
\hline DMU9 & 0.000 & 0.000 & 0.000 & 67.226 & 78.407 & 0.000 & 1.895 & 0.412 & 1.069 & $\overline{\mathrm{DE}}$ & g scale \\
\hline DMU10 & 0.000 & 0.000 & 0.000 & 117.419 & 89.907 & 0.000 & 6.020 & 0.408 & 2.073 & ient & ng scale \\
\hline DMU11 & 000 & .000 & 0.000 & 0.0 & 0.000 & 0.000 & 0.000 & 1.000 & 1.000 & DEA effective & Scale inva \\
\hline DMU12 & 0.000 & 0.000 & 0.000 & 0.000 & 0.000 & 0.000 & 0.000 & 1.000 & 1.000 & DEA effective & Scale invariant \\
\hline
\end{tabular}

According to the value of the column in Table 3, it can be seen that: DMU2, DMU3, DMU5, DMU7, DMU11 and DMU12 are DEA effective, namely effective both in scale and technology, the rest 6 decision-making unit $\theta$ values are less than 1, The effectiveness of the technology needs to be further judged by the $\mathrm{C}^{2} \mathrm{GS}^{2}$ model, the calculation results as shown in table 7 :

Table 4 results of $\mathrm{C}^{2} \mathrm{GS}^{2}$ model

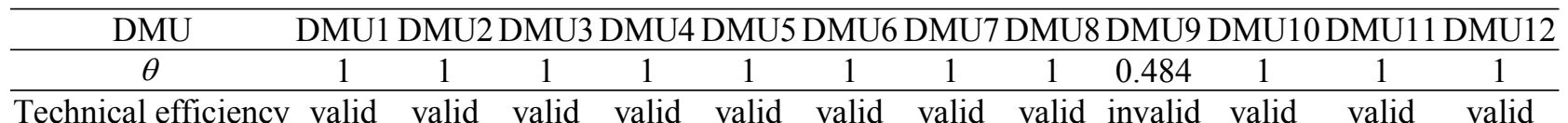

\section{(1) Overall effectiveness analysis}

According to the calculation results of table 3, the DMU2, DMU3, DMU5, DMU7, DMU11 and DMU12's $\theta$ values and $\sum \lambda_{j}^{*}$ values are all equal to 1 , which means that the 6 schools are in the forefront of effective production, the actual meaning is: if the 12 colleges and universities have to keep the existing personnel and funding level, then the 6 schools are the best combination of input elements, while the output level is the most ideal; While the remaining 6 schools, $\theta$ values are less than 1, it is not DEA efficient, there are five of the $\sum \lambda_{j}^{*}$ value is greater than 1, illustrate its scale is in a state of decline, one of the value of $\sum \lambda_{j}^{*}$ is less than 1 , shows that the scale efficiency is in the increasing state. The emergence of this situation, it shows that in some aspects of resource redundancy or the use of efficiency is not high, the level of lack of specific management or technical level, it need to determine by C2GS2 model.

\section{(2) Economies of scale and technological effectiveness analysis}

Analysis the last column of table 3, DMU2, DMU3, DMU5, DMU7, DMU11 and DMU12 has reached the optimal state of scale, while the remaining six DMU, there are five is in a state of diminishing scale, and one is in the condition of increasing economies of scale, this also means that these school did not get to maximize returns.

Analysis columns 2 and 3 of slack variable of input index values in table 3, only DMU 9's $s_{1}^{-}$ value is non-zero, the remaining 11 are zero,indicating that personnel efficiency of input use is very good; about the value of $s_{2}^{-}$, all values of DMU is zero, shows very high efficiency of input use of scientific research funds, and there is no redundant.Comprehensive two remaining variable values, it can be seen that in the resources under the premise of using fully, non-DEA effective of 6 Universities are serious deficiencies in terms of research output; to achieve DEA effective, it must improve the conversion rate of resources from the scientific research assessment and monitoring system and management level, or to maintain the current output of the case, a substantial reduction of personnel and capital investment.

Finally, analysis of the data in Table 4, combined with the information in Table 3, the 12 schools can be divided into three types, the first one is, DMU2, DMU3, DMU5, DMU7, DMU11 and DMU12, they are both DEA effective and technology effective; The second is DMU1, DMU4, 
DMU6, DMU8, DMU10, its $\theta$ value is equal to 1 , indicating that technical efficiency of these five schools are in the best condition, but it is not DEA effective, combined with the analysis results in Table 3, these five schools are non-scale active, so, as long as they find ways to improve economies of scale, they can achieve DEA effective state. The third is DMU9, this school is neither DEA efficient nor technology effectively,for invalid scale, it can be considered by adjusting the projection method for invalid inputs of unit, the proportion of compression while maintaining output unchanged to improve, and the ineffective treatment is related to the The researchers own scientific research ability, scientific research team construction, scientific research system, scientific and normative.

\section{(3)Projection analysis of DMU on the front face of effective production}

From the basic principle of DEA method, for a non DEA efficient decision making units, through the formula (11), (12) to adjust the input and output data, can reach the state of the DEA efficient .This is a process to improve the relative performance of decision making units. Adjust data for the above non DEA effective 6 schools, before and after the adjustment of the data as shown in Table 5.

Table 5 results of DMU projection analysis

\begin{tabular}{|c|c|c|c|c|c|c|c|c|c|c|c|c|c|c|c|}
\hline School Name & DMU & $\begin{array}{c}\mathrm{X} 1 \\
\text { (before) }\end{array}$ & $\begin{array}{c}\mathrm{X} 1 \\
\text { (after) }\end{array}$ & $\begin{array}{c}\mathrm{X} 2 \\
\text { (before) }\end{array}$ & $\begin{array}{c}\mathrm{X} 2 \\
\text { (after) }\end{array}$ & $\begin{array}{c}\text { Y1 } \\
\text { (before) }\end{array}$ & $\begin{array}{c}\text { Y1 } \\
\text { (after) }\end{array}$ & $\begin{array}{c}\text { Y2 } \\
\text { (before) }\end{array}$ & $\begin{array}{c}\mathrm{Y} 2 \\
\text { (after) }\end{array}$ & $\begin{array}{c}\mathrm{Y} 3 \\
\text { (before) }\end{array}$ & $\begin{array}{c}\text { Y3 } \\
\text { (after) }\end{array}$ & $\begin{array}{c}\text { Y4 } \\
\text { (before) }\end{array}$ & $\begin{array}{c}\mathrm{Y} 4 \\
\text { (after) }\end{array}$ & $\begin{array}{c}\text { Y5 } \\
\text { (before) }\end{array}$ & $\begin{array}{c}\text { Y5 } \\
\text { (after) }\end{array}$ \\
\hline $\begin{array}{l}\text { shaoguan } \\
\text { university }\end{array}$ & DMU1 & 52 & 44.8 & 13177 & 11354.4 & 116 & 116 & 237 & 237 & 0 & 84.7 & 0 & 0 & 0 & 1.3 \\
\hline $\begin{array}{l}\text { zhanjiang } \\
\text { normal } \\
\text { university }\end{array}$ & DMU4 & 181 & 149.1 & 21460 & 17668.2 & 258 & 258 & 350 & 369.3 & 0 & 0.6 & 1 & 1 & 0 & 5.5 \\
\hline $\begin{array}{c}\text { Jiaying } \\
\text { University }\end{array}$ & DMU6 & 204 & 112.1 & 19177 & 17102.1 & 124 & 136.2 & 460 & 460 & 0 & 122.9 & 1 & 1 & 1 & 5.5 \\
\hline $\begin{array}{l}\text { Guangdong } \\
\text { petroleum and } \\
\text { Chemical } \\
\text { Engineering } \\
\text { Institute }\end{array}$ & DMU8 & 238 & 127.5 & 51654 & 27677.8 & 434 & 434 & 478 & 483.4 & 0 & 20.5 & 0 & 0 & 0 & 1.7 \\
\hline $\begin{array}{c}\text { Dongguan } \\
\text { University of } \\
\text { technology }\end{array}$ & DMU9 & 144 & 59.4 & 57346 & 23637.3 & 318 & 318 & 275 & 342.2 & 0 & 78.4 & 0 & 0 & 0 & 1.9 \\
\hline $\begin{array}{c}\text { foshan } \\
\text { university }\end{array}$ & DMU10 & 287 & 117.1 & 79988 & 32643.5 & 411 & 411 & 426 & 543.4 & 0 & 89.9 & 1 & 1 & 0 & 6.1 \\
\hline
\end{tabular}

Comparison of the data before and after adjustment, it is found that the Non-DEA effective six decision-making unit of input and output of change is bigger, the input-output ratio shows that the original did not reach the maximization, adjusted according to the principle of projection, personnel and funding both figures are significantly decreased, while the output indexes have different degree rise, this also verifies the previous analysis results.

So, through the comparative analysis, not only can learn its advantages and disadvantages from various universities in the horizontal comparison of the same kind of colleges and universities, but also can adjust the change of indicators, observe the change trend of scientific research, and then take the corresponding improvement measures, ultimately promote the overall scientific research ability of colleges and universities.

\section{Conclusion}

The construction of evaluation index system of university scientific research ability is the basis of the evaluation work, and the use of a variety of evaluation methods is an indispensable tool to complete the evaluation work. Through step by step evaluation method, on the basis of using t-s fuzzy neural network to realize the longitudinal classified, then further use DEA method to transverse comparison of universities' scientific research ability, which can systematically master the self positioning of university scientific research capacity, the advantages and disadvantages of existing and should take the improvement measures, it has a certain practical significance, and the empirical analysis also proves the validity of the model. But because our country is a large country, regional economic development imbalance, and there are obvious regional, diversified and different 
characteristics in different universities and colleges, so this paper builds the index system and evaluation model has some limitations, and in the process of evaluation, how to blend in difficult to quantitative indicators, and thus improve the systematic and scientific evaluation, is also a difficult problem to solve

\section{Reference}

[1]Duan Baobin.Application of Fuzzy Optimization in Evaluating Capability for Scientific Research in Colleges[J]. Journal of Mianyang Normal University.2013,32(11):32-36.

[2]Song Jie. Research on the distribution model of the evaluation of scientific research ability[J]. Intelligence Journal.2001,20(1):4-6.

[3]LI Liang. Evaluation of University Teacher's research ability based on rough set and association rules[J]. Journal of Chongqing University of Technology.2014,28(1):69-74.

[4]Xu Kaiying. Evaluation Model of University Scientific Research Ability Based on SVM Neural Network[J]. Library and information service.2011, 55(22) : 52-55.

[5]Xu Min. Research on the evaluation of scientific research ability in Universities Based on the fuzzy mathematics theory[J]. Research on science and technology management.2006, 24 (8):185187.

[6]Tan Lei. A Comprehensive Evaluation Method of Staff Research Capability at Colleges and Universities:Based on Data Mining[J]. Journal of Northeastern University(Social Science). 2014,16(6):596-600.

[7]Liu Weiwei. Study on Evaluation Index System for Science Research capability of National Defense University based on the Niche Theory[J]. Research on science and technology management. 2010,30(24):45-47

[8]Chen Pin. Research on evaluation index system of University Teachers' scientific research ability[J]. Research on science and technology management.2009, 24 (12):187-188.

[9]Zhu Wen zao. The establishment of systematized evaluation indexes to university scientific research capacity[J]. Journal of Anhui university of technology and science.2003,18(3):40-44.

[10]Zhang Yu. Groundwater Quality Evaluation Based on TSFNN[J]. water saving irrigation. 2012,30(7):35-38.

[11]Hui Xuan. Application of fuzzy neural network in stock price forecasting[J]. Finance \& Economy. 2010,24(20):79-81.

[12]Wei QuanLing. Data envelopment analysis(DEA)[J]. Chinese Science Bulletin. 2000,45(17):1793-1808.

[13]Shi WenLi. Research of Bid Evaluation Model for Electric Power Construction Proj ect Based on Data Envelopment Analysis[D]. ChongQing.Master Thesis of Chongqing University.2004.

[14]Wei QuanLing. Data envelopment analysis[M]. BeiJing:Science Press,2004.

[15] He Li. Evaluation model of scientific research ability in Universities Based on discrete Hopfield neural network[J]. Journal of Wuhan Metallurgical manager's institute.2010,20(3): 65-68

[16]Gao DaWen. Optimization of hidden nodes and training times in artificial neural network[J]. Journal of Harbin institute of technology.2003, 35(2): 45-48. 